\title{
Effects of the Min system on nucleoid segregation in Escherichia coli
}

\author{
Thomas Åkerlund, ${ }^{1} \nmid \neq$ Björn Gullbrand ${ }^{2} \dagger$ and Kurt Nordström²
}

\begin{abstract}
1 Department of Bacteriology, Swedish Institute for Infectious Disease Control, 17182 Solna, Sweden

2 Department of Cell and Molecular Biology, Biomedical Center, Uppsala University, Box 596, S-751 24, Uppsala, Sweden
\end{abstract}

\author{
Author for correspondence: Kurt Nordström. Tel: +461847145 26. Fax: +4618 530396. \\ e-mail: Kurt.Nordstroem@icm.uu.se
}

\begin{abstract}
The Min system of Escherichia coli directs cell division to the mid-cell by a mechanism that involves the dynamic localization of all of its three constituent proteins, MinC, MinD and MinE. Both the Min system and the nucleoid regulate cell division negatively and strains of $E$. coli lacking a functional Min system can divide at nucleoid-free cell poles in addition to the nucleoid-free region between newly segregated nucleoids. Interestingly, $E$. coli strains with a defective Min system have disturbed nucleoid segregation and the cause for this disturbance is not known. It is reported here that growth conditions promoting a higher frequency of polar divisions also lead to a more pronounced disturbance in nucleoid segregation. In strains with an intact Min system, expression of MinE, but not of MinD, from an inducible promoter was followed by impaired nucleoid segregation. These results suggest that the disturbed nucleoid segregation in min mutants is not caused by polar divisions per se, nor by impaired resolution of chromosome dimers in min mutants, leaving open the possibility that the Min system has a direct effect on nucleoid segregation. It is also shown how the disturbed nucleoid segregation can explain in part the unexpected finding that the clear majority of cells in min mutant populations contain $2^{n}(n=0,1,2 \ldots)$ origins of replication.
\end{abstract}

Keywords: cell size, min mutants, minicells

\section{INTRODUCTION}

In Escherichia coli, both the Min system and the nucleoid regulate cell division negatively by preventing the formation of the FtsZ ring, the earliest known step in cell division (Margolin, 2000). The nucleoid inhibits FtsZ ring formation at the regions it occupies (nucleoid occlusion), which normally includes the entire length of the cell except the cell poles and the region between newly segregated nucleoids (Woldringh et al., 1990). It is not yet known by what mechanism nucleoid occlusion occurs.

The Min system consists of three proteins, MinC, MinD and MinE (encoded by the genes $\min C, \min D$ and $\min E$, respectively, forming the $\min B$ operon) and directs cell division to the mid-cell by a mechanism that is independent of the nucleoid. Overexpression of MinC

†Thomas Åkerlund and Björn Gullbrand contributed equally to this work. $\ddagger$ Present address: Department of Molecular and Cell Biology, Division of Biochemistry and Molecular Biology, University of California, Berkeley, CA 94720, USA. and/or MinD results in a block of cell division, whereas overexpression of MinE leads to a phenotype similar to that of a strain lacking all three min genes, including the formation of polar septa and a broad cell size distribution (de Boer et al., 1989). These observations suggest that MinC and MinD acts to block cell division in a non-specific manner and that MinE is required to relieve this inhibition at the mid-cell. MinC has since been shown to interact directly with FtsZ and thereby inhibit the formation of stable FtsZ rings ( $\mathrm{Hu}$ et al., 1999). MinD is a peripheral membrane protein with ATPase activity that binds MinC and recruits it to the cell membrane (de Boer et al., 1991; Hu \& Lutkenhaus, 2000). In the absence of MinD, a 25 -fold increase in the level of MinC is required to inhibit cell division, suggesting that MinD activates MinC by increasing its concentration at the cell membrane (de Boer et al., 1992). Remarkably, all three Min proteins have been shown by GFP fusions to oscillate between the two cell halves (Hu \& Lutkenhaus, 1999; Raskin \& de Boer, 1997, 1999a, b; Hale et al., 2001). MinCD forms a membrane-associated cloud, extending inwards from one cell pole at a time, and MinE forms a ring-like 
structure, probably associated with the innermost edge of the MinCD cloud. MinE has been shown to stimulate the ATPase activity of MinD under certain conditions in vitro (Hu \& Lutkenhaus, 2001). As it is probably only the ATP-bound form of MinD that associates with the membrane, MinE might cause the dissociation of MinD from the membrane by stimulating the ATPase activity of MinD (de Boer et al., 1991; Hu \& Lutkenhaus, 2001). The oscillation means that the time a certain site along the membrane is occupied by MinC increases with its distance from the cell centre. This might explain how the Min system inhibits cell division at sites away from the mid-cell.

Strains lacking a functional Min system have disturbed nucleoid segregation (Jaffé et al., 1988; Mulder et al., 1990; Ảkerlund et al., 1992) and there are several possible explanations for this disturbance. For example, polar divisions might interfere with the partition system. Alternatively, a delayed localization of FtsZ to the cell centre, caused by FtsZ polymerization at the cell poles, might delay the recruitment of FtsK to the cell centre, which is required for the resolution of chromosome dimers (Boyle et al., 2000; Recchia et al., 1999). Results obtained here argue against these explanations, leaving open the possibility that the Min proteins might directly affect nucleoid segregation (Åkerlund et al., 1992). We found that nucleoid distribution in a strain deleted for all min genes (EC1005 $\Delta$ minB) was more disturbed during growth in minimal medium than in rich medium, and the more disturbed nucleoid segregation was associated with a higher frequency of polar septa. Overexpression of MinE impaired nucleoid segregation in cells devoid of polar septa. Overexpression of MinD, on the other hand, had no effect on nucleoid distribution, despite blockage of cell division.

The random selection of division sites in min mutants (Gullbrand \& Nordström, 2000; Teather et al., 1974; Yu \& Margolin, 1999), together with a limited division potential (Donachie \& Begg, 1996; Gullbrand \& Nordström, 2000), has been predicted to result in a population of cells with any number of nucleoids $(1,2$, 3...) (Donachie \& Begg, 1996; Jaffé et al., 1990). However, Jaffé et al. (1990) found that the clear majority of cells in a min mutant population contained $2^{n}$ origins of replication $(n=0,1,2 \ldots)$. Measurements performed here on nucleoid segregation, DNA content and cell size distribution suggest an explanation for this controversy.

In the present communication we present a novel method to study disturbances in nucleoid segregation and use it to compare nucleoid segregation in a $\Delta \min B$ mutant and its wild-type parent. We also present studies of the interdependence of minicell production and cell elongation when a $\mathrm{Min}^{-}$phenotype is induced.

\section{METHODS}

Strains and growth conditions. E. coli strain EC1005 [metB1 nalA relA1 spoT1 $\lambda^{\mathrm{r}} \mathrm{F}^{-}$(Grinsted et al., 1972)] and its minB derivative, EC1005 $\Delta$ minB (Åkerlund et al., 1992) have been described previously. Plasmids pDB156 and pDB164 were generous gifts from Piet de Boer (de Boer et al., 1989) and were transformed into strain EC1005. Transformants were selected for by ampicillin $\left(50 \mu \mathrm{g} \mathrm{ml}^{-1}\right)$. The bacteria were grown in $\mathrm{M} 9$ minimal medium (Sambrook et al., 1989) supplemented with methionine $\left(50 \mu \mathrm{g} \mathrm{ml}^{-1}\right)$ and either $0.2 \%$ glucose (M9gluc), $0.2 \%$ glycerol (M9glyc) or $0.5 \%$ Casamino acids (Difco) and $0.2 \%$ acetate (M9CAace), or in Luria-Bertani medium (LB), with or without $0.2 \%$ glucose (LB and LBgluc, respectively). Ampicillin and kanamycin were added to a final concentration of $20 \mu \mathrm{g} \mathrm{ml}^{-1}$ in M9 medium and $50 \mu \mathrm{g} \mathrm{ml}^{-1}$ in LB medium, where appropriate. All strains were grown at $37^{\circ} \mathrm{C}$. IPTG was used at a final concentration of $1 \mathrm{mM}$ to induce MinE and MinD production from plasmids pDB156 and pDB164, respectively. For replication runout, rifampicin and cephalexin were added simultaneously to final concentrations of 200 and $10 \mu \mathrm{g} \mathrm{ml}^{-1}$, respectively, and samples were taken $120 \mathrm{~min}$ after the addition of the drugs.

Microcolony experiments (Åkerlund et al., 1992). For growth of microcolonies, $10 \mu \mathrm{l}$ of an exponentially growing culture was put on a microscope slide covered with the same growth medium with the addition of $1 \%$ agar. The microscope slides were incubated in a moisture chamber at $37^{\circ} \mathrm{C}$ for $2 \mathrm{~h}$ before inspection by phase-contrast microscopy in a Nikon Optiphot2 microscope. Images were digitized using a cooled CCDcamera (Meridian) and the cell lengths were measured with Image Analysis version 1.80 software (Bergström Instrument). For induction of MinE, $1 \mathrm{mM}$ IPTG was added to the cultures $10 \mathrm{~min}$ before cells were transferred to the agar surface, and $1 \mathrm{mM}$ IPTG was also included in the agar medium.

Microscopic examinations (Åkerlund et al., 1992). Samples from exponentially growing cultures were fixed in $70 \%$ ethanol, centrifuged and resuspended in $0.9 \% \mathrm{NaCl}$, and spread on microscope slides covered with a flat surface of $1 \%$ agar containing $0.9 \% \mathrm{NaCl}$. The cells were observed by phase-contrast in a Nikon Optiphot-2 microscope and the projected cell area $\left(\mu \mathrm{m}^{2}\right)$ was measured using software from Bergström Instrument. Inter-nucleoid distances were measured using the following method. First, wild-type and min mutant cells within a size range corresponding to a wild-type mother cell were chosen for each growth medium (see legend to Fig. 1). Next, the fluorescence intensities of the nucleoids in DAPI-stained cells of this size group were outlined using a grey-scale profile plot tool provided in the image analysis software. To account for differences in fluorescence intensities between cells, the mean of the peak intensities of the nucleoids located at about $1 / 4$ and $3 / 4$ of the total cell length was set to 1. Cells with deep constrictions were omitted from the analysis.

Flow cytometry analysis. For flow cytometry, $1 \mathrm{ml}$ cell culture was centrifuged at $15000 \mathrm{~g}$ for $7 \mathrm{~min}$, resuspended in $0.35 \mathrm{ml}$ $0.9 \% \mathrm{NaCl}$ and fixed by the addition of $1 \mathrm{ml} 95 \%$ ethanol. Samples were stored at $4{ }^{\circ} \mathrm{C}$. Before analysis, the cells were centrifuged at $4^{\circ} \mathrm{C}$, washed in $1 \mathrm{ml} 10 \mathrm{mM}$ Tris buffer $\left(4^{\circ} \mathrm{C}\right.$, $\mathrm{pH} 7.5$, adjusted at room temperature) containing $10 \mathrm{mM}$ $\mathrm{MgCl}_{2}$, centrifuged again and resuspended in an appropriate amount of the same buffer. The DNA was stained by mixing $65 \mu \mathrm{l}$ of the cell suspension with $65 \mu \mathrm{l}$ buffer containing ethidium bromide $\left(40 \mu \mathrm{g} \mathrm{ml}^{-1}\right)$ and mithramycin A $\left(200 \mu \mathrm{g} \mathrm{ml}^{-1}\right)$. Samples were analysed on a Bryte-HS flow cytometer (Bio-Rad), calibrated with fluorescent beads. Light scatter and fluorescence signals were divided into 256 channels each and the number of particles in each channel was monitored by WinBryte version 2.03 software (Bio-Rad). At least 75000 cells were measured in each sample. The number 
of chromosomes represented by the positions of the peaks shown in Fig. 5 were determined by comparisons to the peak positions obtained from cultures grown to stationary phase and which were known to contain cells with one chromosome (Gullbrand \& Nordström, 2000).

\section{RESULTS}

Nucleoid segregation, polar division frequency and cell-size distribution vary between growth media in min mutants

Assuming a random selection of division sites and a limited division potential, min mutants should have a constant frequency of polar septa and a characteristic cell-size distribution (Donachie \& Begg, 1996; Teather et al., 1974). In LBgluc, cells of strain EC1005 $\Delta$ minB were 1.6- to 1.7-fold larger than EC1005 (Table 1) as predicted and as measured by Teather et al. (1974). In M9gluc and M9CAace, however, the cell-size distribution was broader than in LBgluc and the frequency of polar septa was higher (Table 1, Fig. 1). The mean size of EC1005 $\Delta \operatorname{minB}$ was $1 \cdot 9$ - and 2.0-fold larger than EC1005 in M9gluc and M9CAace, respectively (Table $1)$. The relative size distribution of EC1005 $\Delta$ minB in LBgluc was significantly different from that in M9gluc and M9CAace (see Fig. 4b); a $\chi^{2}$ test gave $\chi^{2}=$ $32>\chi_{0.005[8]}^{2}$ between LBgluc and M9gluc. A comparison between M9gluc and M9CAace gave $\chi^{2}=9 \cdot 2<\chi_{0 \cdot 1[8]}^{2}$, i.e. an insignificant difference.

To investigate if the disturbances in nucleoid segregation were more pronounced in minimal medium, an accurate and objective method based on image analysis was developed to measure nucleoid segregation. The method relies on measurements of the fluorescence intensity between nucleoids in cells stained with DAPI (Fig. 2). A low value indicates that nucleoids are well segregated and that no DNA remains in the centre of the cells. A population of cells about twice the size of a newborn wild-type cell was chosen for analysis. Wild-type cells in this size range are close to dividing and often have a clear gap or decrease in DAPI staining at their cell centre. A difference in nucleoid segregation between wild-type and min mutant cells should therefore be easier to detect in cells of this size range than in shorter cells. It should also be stressed that the growth rate was the same for the wild-type and the min mutant. Three examples of cells stained with DAPI, together with the corresponding profile plots, are shown in Fig. 2(a). Cell 1 did not contain visibly separated nucleoids and, accordingly, the corresponding profile plot did not show any detectable minimum in the centre (Y1). Cells 2 and 3 contained nucleoids with better separation and the profile plots showed two visible minima, Y2 and Y3. The micrographs show that cell 3 had a more clear gap between the nucleoids than cell 2 , and the $Y$ value of cell 3 (Y3) was, as expected, lower than that of cell 2 (Y2). The $Y$ values of about 300 cells from each culture were plotted in cumulative frequency plots, showing the distribution of all $Y$ values in each population. The $Y$ values for the wild-type cells were found to be lower than those of the min cells in all cultures tested (Fig. $2 \mathrm{~b}-\mathrm{d})$. In LBgluc, about $60 \%$ of the wild-type and $25 \%$ of the min population had $Y$ values lower than 0.7 (Fig. 2b). In M9gluc, the corresponding values were 60 and $10 \%$ (Fig. 2c), implying that the nucleoid disturbances were larger in M9gluc than in LBgluc.

Table 1. Cell size and polar division frequency of cells of EC1005 and EC1005 $\Delta \min B$ in different media

\begin{tabular}{|c|c|c|c|}
\hline Strain, medium* & $\begin{array}{l}\text { Mean cell size } \\
\left(\mu \mathrm{m}^{2}\right) \pm \mathrm{SE}(\boldsymbol{n}) \dagger\end{array}$ & $\begin{array}{l}\text { Relative size of } \\
\text { min mutant } \ddagger\end{array}$ & $\begin{array}{c}\text { Fraction of } \\
\text { constricting cells with } \\
\text { polar septa }(n) \mathbb{S}\end{array}$ \\
\hline \multirow[t]{2}{*}{ EC1005, LBgluc } & $5 \cdot 27 \pm 0 \cdot 08(516)$ & & \\
\hline & $5 \cdot 52 \pm 0 \cdot 07(516)$ & - & - \\
\hline \multirow[t]{2}{*}{ EC1005 $\Delta \min B$, LBgluc } & $8 \cdot 53 \pm 0 \cdot 24(505)$ & $1.62 \pm 0.07$ & $0.36 \pm 0.02(559)$ \\
\hline & $9 \cdot 26 \pm 0 \cdot 26(502)$ & $1 \cdot 68 \pm 0 \cdot 07$ & \\
\hline EC1005, M9gluc & $1.90 \pm 0.02(997)$ & - & - \\
\hline EC1005 $\Delta$ min $B$, M9gluc & $3.59 \pm 0.06(935)$ & $1 \cdot 89 \pm 0 \cdot 05$ & $0 \cdot 60 \pm 0 \cdot 04(285)$ \\
\hline EC1005, M9CAace & $2 \cdot 06 \pm 0.03(509)$ & - & - \\
\hline EC1005 $\Delta \min B$, M9CAace & $4 \cdot 16 \pm 0 \cdot 08(508)$ & $2 \cdot 02 \pm 0 \cdot 07$ & $0.51 \pm 0.03(534)$ \\
\hline
\end{tabular}

*LBgluc, Luria Broth + 0.2\% glucose; M9gluc, M9 medium + 0.2\% glucose (Sambrook et al., 1989); M9CAace, M9 medium $+0 \cdot 5 \%$ Casamino acids $+0 \cdot 2 \%$ acetate.

† Cell size was measured as the projected area using phase-contrast microscopy combined with image analysis. Two different experiments are reported for LBgluc.

¥ The relative size was obtained by dividing the mean size of EC1005 $\Delta \mathrm{minB}$ by that $\mathrm{EC} 1005$.

$\mathbb{S}$ The number of cells with polar septa was divided by the total number of constricted cells counted (the total number of cells that were scored is shown within parentheses). Cells containing several septa of the same kind were scored as one, and cells with both polar and non-polar septa were scored once in each group. 

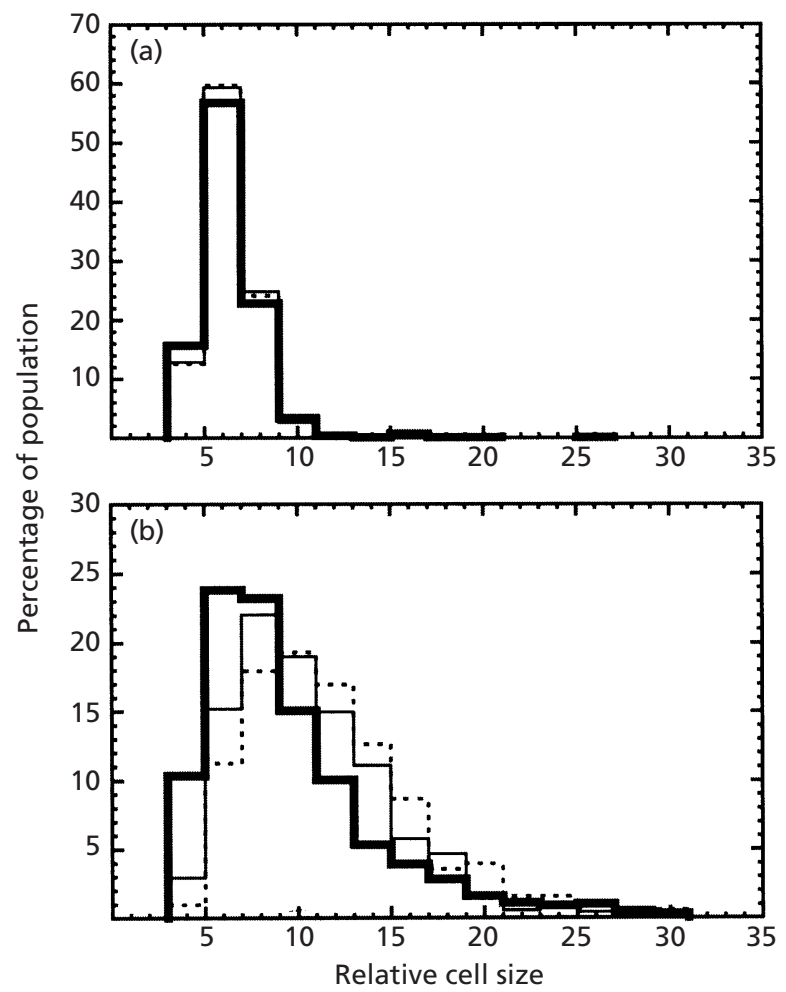

Fig. 1. Relative size distributions of wild-type EC1005 (a) and mutant EC1005 $\Delta \min B(b)$, respectively, in LBgluc (bold line), M9CAace (dotted line) and M9gluc (thin line). The $x$-axis shows the actual cell size in LBgluc medium. To superimpose the histograms obtained in M9gluc and M9CAace, the size values were multiplied by factors 2.8353 and 2.6229 , respectively. These factors were obtained by dividing the wild-type mean size in LBgluc by the mean sizes for the wild-type in M9gluc or M9CAace (Table 1). Two different experiments were performed in LBgluc (Table 1) and the cell size values were pooled.

In conclusion, the frequency of polar septa was higher and the deviation from the wild-type cell-size distribution and disturbance in nucleoid segregation were larger for EC1005 $\Delta$ minB grown in minimal medium than for EC1005 $\Delta$ minB grown in rich medium.

\section{Nucleoid segregation is impaired by overexpression of MinE}

Overexpression of MinE in a wild-type strain causes a $\mathrm{Min}^{-}$phenotype (de Boer et al., 1989). By inducing MinE expression from a MinE expression vector (pDB156), we could therefore investigate whether the characteristics of the $\mathrm{Min}^{-}$phenotype appeared in any specific order (formation of polar septa, a decreased frequency of non-polar septa and a disturbed nucleoid segregation).

In the microcolony experiments, populations of strain EC1005(pDB156) were grown exponentially in M9gluc medium. To induce MinE synthesis, IPTG $(1 \mathrm{mM})$ was added and after further incubation for 10 min samples (a)
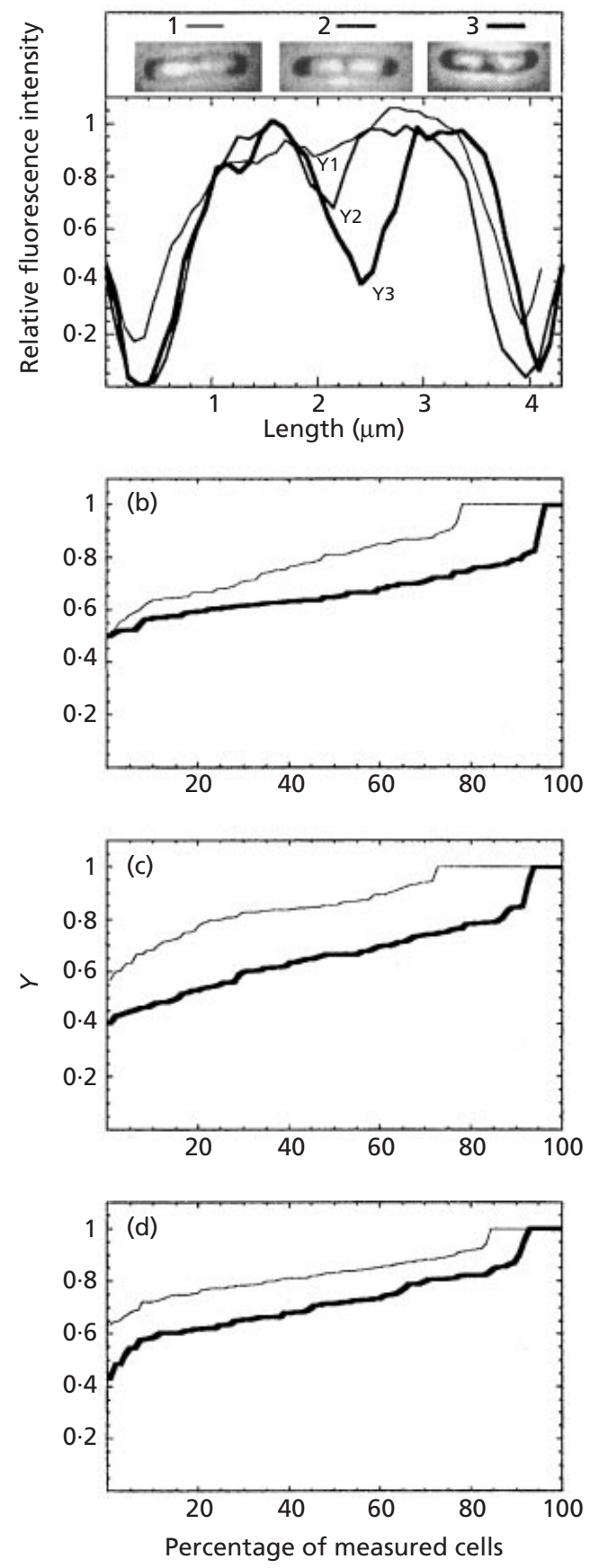

Fig. 2. Segregation of nucleoids in wild-type and min mutant cells in different media. Cells that were within a size range twice that of a newborn cell were chosen for analysis as follows (the values within parentheses represent the fraction of the total wild-type population that was within the specified size range): LBgluc, $6-8 \mu \mathrm{m}^{2}$ (0.20); M9gluc, 2.2-3.0 $\mu \mathrm{m}^{2}$ (0.22); M9CAace, $2 \cdot 4-3 \cdot 2 \mu \mathrm{m}^{2}(0 \cdot 19)$. The nucleoid profiles were obtained from fixed, DAPI-stained cells using combined phase and fluorescence microscopy (Åkerlund et al., 1992) and a profile-plot tool in the image analysis software. The minimum value $(Y)$ in the centre of each profile was scored for about 90 wild-type and min mutant cells. (a) Three DAPI-stained wildtype cells (1-3), together with their corresponding and normalized profile plots. $\mathrm{Y} 1-\mathrm{Y} 3$ indicate the minimum values between the nucleoids. (b) Cumulative frequency plots of $Y$ 
Table 2. Frequency of minicells in microcolonies $2 \mathrm{~h}$ after induction of MinE [EC1005(pDB156)] by $1 \mathrm{mM}$ IPTG in M9gluc

Results shown are mean values of two experiments.

\begin{tabular}{|c|c|c|c|c|c|}
\hline \multirow[t]{2}{*}{ IPTG } & \multicolumn{2}{|c|}{$\begin{array}{l}\text { Frequency of cells } \\
\text { with septa }\end{array}$} & \multirow[t]{2}{*}{$\begin{array}{l}\text { Frequency of microcolonies with minicells } \\
\text { or cells with polar septa* }\end{array}$} & \multicolumn{2}{|c|}{$\begin{array}{l}\text { Mean cell length in colonies without } \\
\text { minicells }(\mu \mathrm{m})\end{array}$} \\
\hline & Non-polar & Polar & & Non-septated & $\begin{array}{l}\text { Non-polar } \\
\text { septated }\end{array}$ \\
\hline- & $0 \cdot 21$ & $<0.005$ & $<0.01$ & $3 \cdot 0$ & $4 \cdot 1$ \\
\hline+ & $0 \cdot 10$ & $0 \cdot 03$ & $0 \cdot 33$ & $3 \cdot 8$ & $5 \cdot 2$ \\
\hline
\end{tabular}

* The mean number of cells was 4.9 in the absence and 2.9 in the presence of IPTG, respectively, and the mean total cell length in the microcolonies was $15.7 \mu \mathrm{m}$ in the absence and $12.4 \mu \mathrm{m}$ in the presence of IPTG, respectively.

were diluted and plated on microscope slides containing the same medium with $1 \mathrm{mM}$ IPTG. The plated cells were allowed to grow for $2 \mathrm{~h}$ on the plates before examination under the microscope. During this period, only a few cell doublings occurred (see footnote to Table 2).

In microcolony experiments in M9gluc medium, $33 \%$ of the colonies contained minicells or cells with polar septa $2 \mathrm{~h}$ after induction with IPTG (Table 2). In colonies lacking minicells, the mean cell size had increased as compared to the non-induced culture (Table 2). Thus, a reduced frequency of non-polar divisions was not preceded by the formation of polar septa/minicells. After induction of MinE in M9gluc batch cultures, the cell size increased, although there was a slight size increase also in the non-induced control culture over time (Fig. 3a). At 20 min the frequency of septating cells had decreased and at 40 min the frequency of cells with polar septa had increased (Fig. 3b; Table 3). At $60 \mathrm{~min}$ the frequency of cells with polar septa was similar to that of the cells with non-polar septa in the control culture. A similar result was obtained when the same experiment was performed in LB medium, although the relative frequency of polar divisions was lower than in M9gluc (Table 3).

The nucleoid segregation was analysed 20 and $40 \mathrm{~min}$ after the addition of IPTG. We chose to measure only relatively large cells; $2 \cdot 2$ to $3 \mu \mathrm{m}^{2}(20-25 \%$ of the total populations), to compare nucleoid segregation in dividing cells or in cells likely to divide within a short period of time. At both 20 and $40 \mathrm{~min}$, the $Y$ values were higher in the culture induced with IPTG (Fig. 3c, d). No or very few cells in the 20 min samples had a polar septum (Table 3 ) and it is thus unlikely that the disturbed nucleoid structure was caused by the formation of polar septa. A similar result was found in LB medium upon induction of MinE (not shown).

values obtained for wild-type cells (bold line) and the min mutant (thin line) in LBgluc. (c) As for (b) but in M9gluc. (d) As for (b) but in M9CAace.

\section{Nucleoid segregation is not affected by overexpression of MinD}

Localization of FtsZ to the cell centre is required for recruitment of FtsK to the cell centre (Yu et al., 1998), and FtsK in turn is essential for the resolution of chromosome dimers (Boyle et al., 2000; Recchia et al., 1999). Since min mutants have a decreased frequency of non-polar divisions and thereby possibly a higher frequency of chromosome dimers, it is possible that the impaired nucleoid segregation observed in min mutants reflects a higher frequency of chromosome dimers. Here, we investigated nucleoid segregation after overexpression of MinD, which blocks cell division, probably at the stage of FtsZ polymerization (Hu et al., 1999) and thus prevents the resolution of chromosome dimers. MinD overexpression was induced from the expression vector pDB164 (de Boer et al., 1989) with 1 mM IPTG. As expected, the cell size increased and the frequency of constricting cells decreased (Fig. 4a, b). The distribution of $Y$ values at $40 \mathrm{~min}$ after induction was nearly identical to that of the non-induced culture (Fig. 4c). Thus, overexpression of MinD and inhibition of cell division, and thereby inhibition of resolution of chromosome dimers, had no affect on nucleoid segregation, as measured here.

\section{Division pattern in min mutants}

A random selection of division sites in combination with a limited division potential in a minicell-producing strain has been predicted to lead to the production of cells with any number of nucleoids (Donachie \& Begg, 1996; Jaffé et al., 1990). The finding of Jaffé et al. (1990) that very few cells in a $\Delta$ minB strain contained a number of origins of replication not equal to $2^{n}(n=0,1,2 \ldots)$ is therefore surprising. This result was found by flow cytometry during analysis of the number of chromosomes per cell after a replication runout, where each chromosome represented one origin of replication before the runout. Replication runout was achieved by inhibition of initiation of replication by addition of rifampicin and cell division was inhibited by addition of cephalexin. Using the same approach, we obtained a 

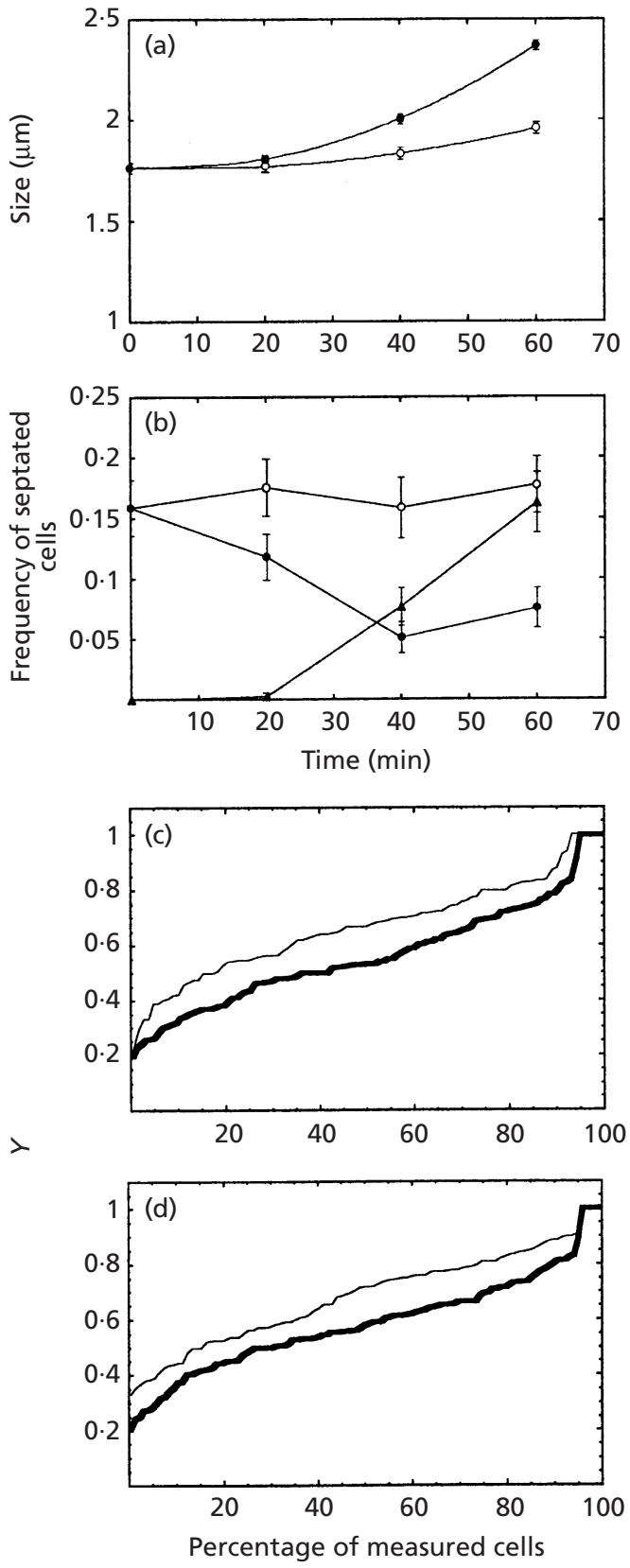

Fig. 3. Cell size, division kinetics and nucleoid segregation during induction of MinE synthesis. A culture of EC1005 containing plasmid pDB156 in M9gluc was split into two and $1 \mathrm{mM}$ IPTG was added to one of the cultures (time zero). Samples were taken at different time-points and analysed. (a) Mean cell size $+(\mathbf{O})$ or $-(O)$ IPTG. (b) Frequency of septated cells $+(\boldsymbol{\Delta}$, polar septa; $\boldsymbol{0}$, non-polar septa) or - (O) IPTG. (c) Nucleoid segregation $20 \mathrm{~min}$ after induction. The non-induced culture (-IPTG, control) is shown as a bold line. (d) As for (c), but 40 min after induction. For details, see legend to Fig. 2 and Methods.

similar result for EC1005 $\Delta$ minB grown in M9gluc; $89 \%$ of the cells contained $2^{n}$ origins of replication per cell, as compared to $93 \%$ for EC1005 (Fig. 5). Even higher proportions of cells containing $2^{n}$ origins of replication were obtained for EC1005
M9glycerol and LBgluc. Thus, the random selection of division sites in EC1005 $\Delta$ minB only lead to a very small increase in the proportion of cells with a number of origins not equal to $2^{n}$.

To investigate this controversy between the predicted and observed number of origins of replication, we analysed the DNA-content and cell-size distribution of EC1005 $\Delta \min B$ grown in M9gluc. As EC1005 $\Delta \min B$ grown in M9gluc had a generation time of about $40 \mathrm{~min}$, all chromosomes were assumed to have ongoing chromosome replication and cells with an odd number of chromosomes after the replication runout were therefore not expected (Helmstetter \& Cooper, 1968). About $24 \%$ of the cells of EC1005 $\triangle$ minB contained eight origins of replication, as compared to only $10 \%$ for EC1005 (Fig. 5). To investigate the possibility that the cells with eight origins of replication could divide at the cell quarter positions to produce cells with six and two origins of replication, we estimated the minimum cell length at which this could occur. We used the flow cytometry results shown in Fig. 5, together with the celllength distributions of the same populations (the length of at least 340 cells from samples taken before the addition of rifampicin and cephalexin was measured by microscopy), to estimate the cell length at which cells of EC1005 $\Delta$ minB gained eight origins of replication and at which division at the cell quarter positions could occur.

About $36 \%$ of the cells of EC1005 $\operatorname{minB}$ contained eight or more origins of replication, which corresponded to a cell length of $4.8 \mu \mathrm{m}$ or more. The mean cell length for cells of EC1005 was $2 \cdot 8 \mu \mathrm{m}$ and this would correspond to a cell length of $2 \cdot 1 \mu \mathrm{m}$ for newborn cells, on the assumption that the cell-size distribution of EC1005 was ideal for an exponentially growing population. If a non-polar cell-division event in EC1005 and EC1005 $\Delta$ minB required the same increase in cell length, non-polar, non-central division events in EC1005 $\Delta$ minB would not occur until a cell length of $4 \times 2 \cdot 1 \mu \mathrm{m}=8 \cdot 4 \mu \mathrm{m}$ was reached. Since the nucleoid segregation was markedly delayed in EC1005 $\operatorname{minB}$ grown in M9gluc, this is probably an underestimation of the minimum cell length at which cell division could occur at the cell quarter positions. It is therefore likely that there was a substantial period of time after the cells had gained eight origins of replication, during which they could not divide at the cell quarter positions.

The actual distributions of septa for the populations shown in Fig. 5 were estimated by microscopy and are shown in Fig. 6. Although a majority of cells longer than $4.8 \mu \mathrm{m}$ had central septa (56\% of the non-polar septa in cells longer than $4.8 \mu \mathrm{m}$ were found within $10 \%$ of the cell length from the cell centre), many cells shorter than $8.4 \mu \mathrm{m}$ had non-polar, non-central septa. The presence of these septa might in part be explained by the fact that some of these cells had recently undergone cell division and before that had been longer than $8.4 \mu \mathrm{m}$. Another explanation might be that the cell centre was less exactly determined in the absence of the Min system. It seems, however, that the observed frequency of non-polar, noncentral divisions would lead to a higher frequency of 
Table 3. Cell division kinetics after induction of MinE (pDB156) and MinD (pDB164) in a wild-type strain

\begin{tabular}{|llccc|}
\hline Strain & Medium, time $(\mathbf{m i n})^{* *}$ & IPTG & \multicolumn{2}{c|}{ Frequency of cells with septa $\dagger$} \\
\cline { 3 - 4 } & & & Non-polar & Polar \\
\hline \multirow{2}{*}{ EC1005(pDB156) } & M9gluc, 20 & - & $0 \cdot 17$ & $<0 \cdot 003$ \\
& M9gluc, 40 & - & $0 \cdot 16$ & $<0 \cdot 003$ \\
& M9gluc, 20 & + & $0 \cdot 12$ & $0 \cdot 003$ \\
& M9gluc, 40 & + & $0 \cdot 05$ & $0 \cdot 08$ \\
& LB, 30 & - & $0 \cdot 31$ & $<0 \cdot 003$ \\
LB, 30 & + & $0 \cdot 11$ & $0 \cdot 03$ \\
EC1005(pDB164) & M9gluc, 40 & - & $0 \cdot 16$ & $<0 \cdot 003$ \\
& M9gluc, 40 & + & $0 \cdot 04$ & $0 \cdot 006$ \\
\hline
\end{tabular}

*At time zero, the culture was divided into two, and one of the cultures was induced by $1 \mathrm{mM}$ IPTG. The samples were collected 20 and $40 \mathrm{~min}$ (M9gluc) or $30 \mathrm{~min}$ (LB) after IPTG induction.

† About 300 cells were counted.

cells with six origins of replication, than what was obtained by flow cytometry $(2.7 \%$, Fig. 5$)$. This discrepancy might in part be due to a shorter interdivision time after divisions at, e.g., quarter positions. This seems reasonable since when division occurs at a cell quarter position, nucleoid segregation can be expected to be relatively far advanced also at the other quarter position and, if not permanently blocked, also at the cell centre.

\section{DISCUSSION}

The main findings in the present communication are (i) a novel method to study disturbances in nucleoid segregation, (ii) that nucleoid segregation in a $\Delta \min B$ mutant was disturbed compared to its wild-type counterpart, (iii) that induction of the $\mathrm{Min}^{-}$phenotype by overexpression of the $\min E$ gene caused disturbances in nucleoid segregation and that elongation of the cells did not require minicell production, and (iv) that our data do not support the quantal theory of cell division presented by Teather et al. (1974).

We used a novel method to quantify nucleoid segregation in the wild-type and a $\Delta \min B$ mutant. The comparison was made with cells in the size range of dividing wild-type cells. It should be stressed that the growth rate was the same for the wild-type and the $\Delta \min B$ mutant. We found that nucleoid segregation was delayed in the $\triangle \min B$ mutant in the three different media used. We further found that nucleoid segregation in EC1005 $\Delta \min B$ was more disturbed during growth in minimal medium than in rich medium. The more disturbed nucleoid segregation in minimal medium was associated with an increased frequency of polar septa and a broader cell-size distribution. Although the ability to form polar septa was caused by the absence of a functional Min system, we speculate that the increased frequency of polar septa seen in minimal medium was caused by the more disturbed nucleoid segregation. This might have been due to unsegregated nucleoids at the cell centre, forcing cell division to occur at the cell poles. As disturbances in nucleoid segregation were observed before polar septa after induction of MinE, it seems less likely that the more disturbed nucleoid segregation in EC1005 $\Delta$ minB grown in minimal medium was caused by the increased frequency of polar septa. The larger deviation from the wild-type cell-size distribution of EC1005 $\Delta$ minB in minimal medium might have been caused by both the more disturbed nucleoid segregation and the increased frequency of polar septa.

Although the effect of growth medium on nucleoid segregation in EC1005 $\Delta$ minB is striking, there seems to be no obvious explanation for this effect. Nucleoids in cells grown in a rich medium appear to be divided into distinct lobules, as visualized by DAPI staining. No such structures can be seen for cells grown in minimal medium, where the nucleoids seem to fill out the cells uniformly. It is possible that these differences in apparent nucleoid structure could somehow directly affect the results of our measurements and/or nucleoid segregation in the absence of a functional Min system.

Overexpression of MinD inhibited cell division, but had no detectable effect on nucleoid segregation. Since cell division is required for the resolution of chromosome dimers (Boyle et al., 2000; Recchia et al., 1999; Yu et al., 1998), it is probable that the disturbances in nucleoid segregation observed in min mutants are not caused by an impaired resolution of chromosome dimers. Also, the disturbances in nucleoid segregation did not require the formation of polar septa. It is thus possible that the disturbed nucleoid segregation is a direct effect of a nonfunctional Min system. If true, both the absence of all Min proteins, as well as overexpression of MinE, but not of MinD, would directly cause the segregation disturbances. Both the nucleoid and MinD are assumed to interact with the cell membrane (de Boer et al., 1991; Nanninga, 1998). It is thus possible that the absence of MinD or some disturbances in its localization would cause the segregation disturbances. From studies 

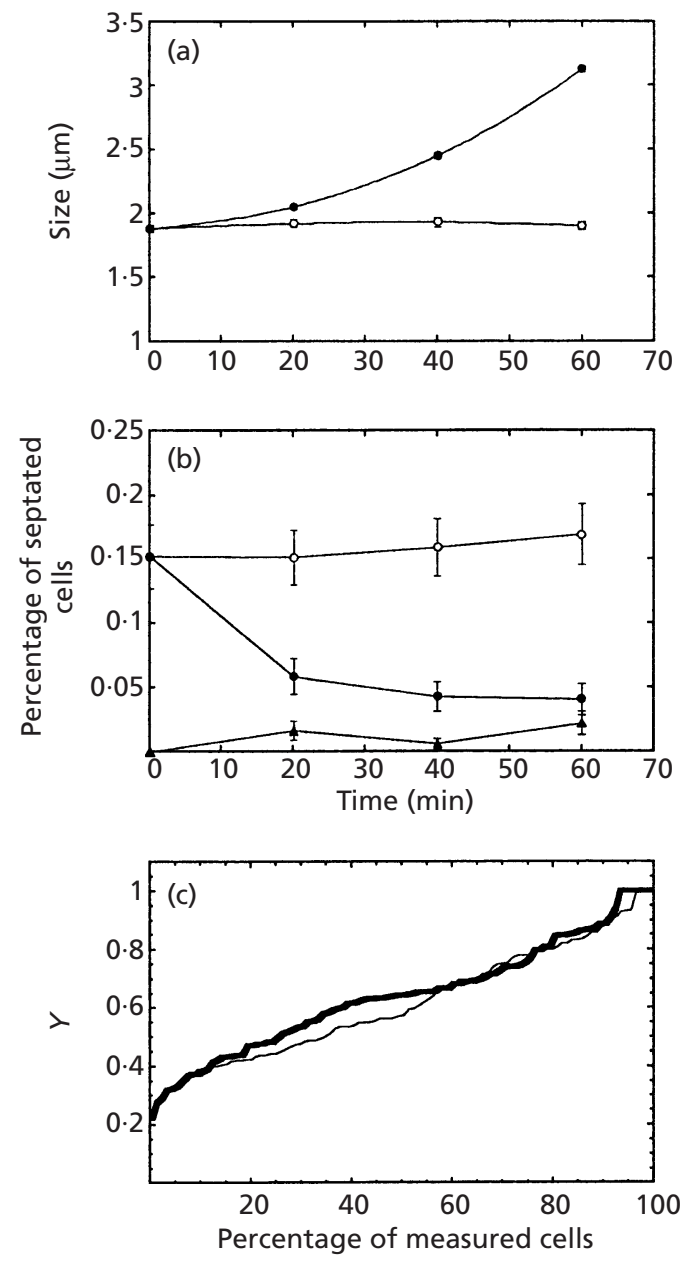

Fig. 4. Cell size, division kinetics and nucleoid segregation during induction of MinD synthesis. A culture of EC1005 containing plasmid pDB164 in M9gluc was split into two and $1 \mathrm{mM}$ IPTG was added to one of the cultures (time zero). Samples were taken at different time-points and analysed. (a) Mean cell size $+(\mathbf{0})$ or $-(O)$ IPTG. (b) Frequency of septated cells $+(\boldsymbol{\Delta}$, polar septa; $\boldsymbol{0}$, non-polar septa) or $-(\bigcirc)$ IPTG. (c) Nucleoid segregation $40 \mathrm{~min}$ after induction. The non-induced culture (-IPTG, control) is shown as a bold line. For details, see legend to Fig. 2 and Methods.

on $\mathrm{Min}^{+}$strains expressing either $g f p$-minD or $g f p$ $\min D E$, the oscillation frequency of MinD was suggested to be inversely related to the MinD : MinE ratio (Raskin $\&$ de Boer, 1999a). However, the expression levels used in this previous study might have been much lower than what was used here, as judging from the different phenotypes obtained. We therefore cannot assume any similar relationship between the oscillatory movement of MinD and the MinD: MinE ratios obtained here.

As shown in Fig. 4(c), overexpression of MinD and inhibition of cell division, and thereby inhibition of resolution of chromosome dimers, had no effect on nucleoid segregation, as measured here. It is possible that the resolution of chromosome dimers occurs too late in the cell cycle to produce a detectable effect on

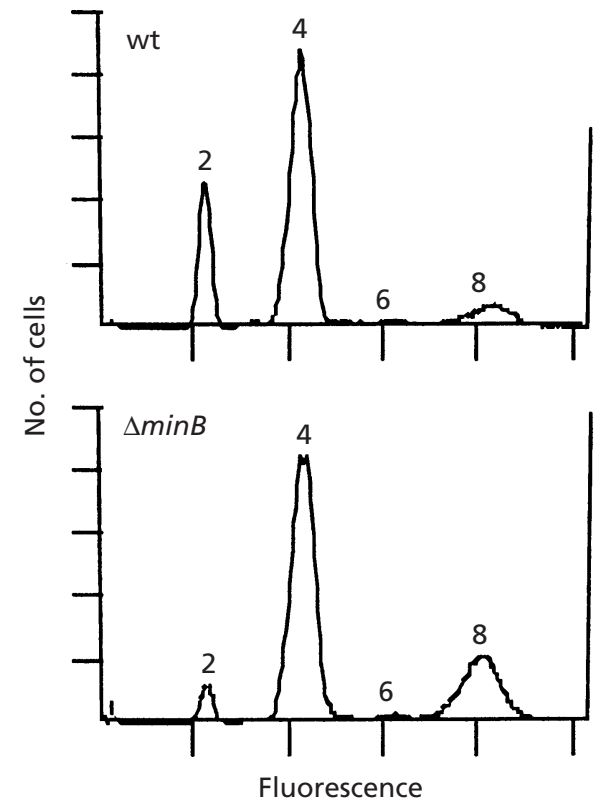

Fig. 5. Number of origins per cell in exponentially growing cultures of EC1005 (wt) and EC1005 $\Delta \min B(\Delta \min B)$. The flow cytometry diagrams show the DNA-content distributions in the cells 120 min after addition of rifampicin and cephalexin to the cultures. The numbers indicate the number of genome equivalents in the cells, corresponding to the number of origins per cell at the time of addition of the drugs. (a)

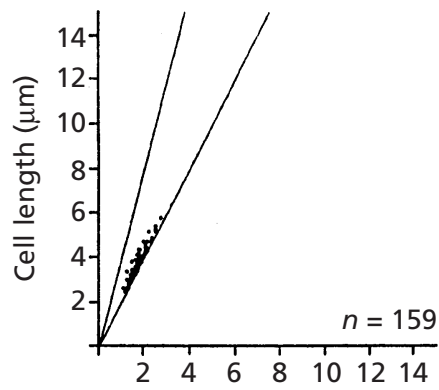

(b)

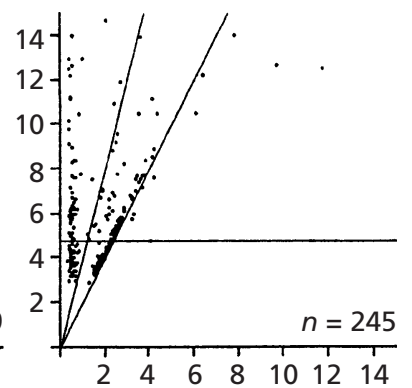

Distance from the septum to the nearest cell pole $(\mu \mathrm{m})$

Fig. 6. Localization of septa in EC1005 (a) and EC1005 $\Delta \min B$ (b). For cells with more than one septum, the distances from the pole closest to a septum are represented. The lines in each diagram represent the cell centre (rightmost line) and the cell quarter position (leftmost line). The horizontal line in (b) represents a cell length of $4.8 \mu \mathrm{m}$, the cell length at which cells gained eight origins of replication, as estimated from flow cytometry analysis and the cell size distribution from the same culture. In (b), 5 cells were longer than $15 \mu \mathrm{m}$ and were not included in the graph.

nucleoid segregation in cells of the sizes measured here. Another factor contributing to the failure to detect chromosome dimers could be that dimers form in only $14 \%$ of all cells (Steiner \& Kuempel, 1998; Pérals et al., 2000). 
Chromosome condensation has recently been suggested to play an important role in nucleoid segregation, by preventing the entanglement of newly replicated DNA and perhaps also by providing a force pulling the two strands of DNA in opposite directions (Nordström \& Dasgupta, 2001). The effects seen here on nucleoid segregation might thus be caused by an impaired chromosome condensation in cells exhibiting the $\mathrm{Min}^{-}$ phenotype. Indeed, Mulder et al. (1990) found a correlation between the level of Min proteins and DNA supercoiling. It is also possible that the degree of superhelicity directly affected the results of our measurements, by affecting nucleoid expansion.

Division potential has been assumed to accumulate as cells grow (Teather et al., 1974) and the major limiting factor for cell division might be FtsZ (Bi \& Lutkenhaus, 1990). The number of septa per unit cell length has been found to be similar in $\mathrm{Min}^{+}$and $\mathrm{Min}^{-}$strains (Donachie \& Begg, 1996), and an increase in cell length corresponding to one newborn $\mathrm{Min}^{+}$cell has therefore been assumed to be required for each cell division. Polar and non-polar division events are assumed to consume equal amounts of division potential and polar division events would thus lead to an increase in the mean cell length for the DNA-containing cells. [It should, however, be noted that this simple quantal behaviour of cell division in minB mutants was questioned by Åkerlund et al. (1992), who reported data suggesting that polar and central divisions are not mutually exclusive.] As cells get longer, more potential division sites would appear and a random selection between these division sites would lead to a population of cells of various lengths and various numbers of origins of replication. Here, the increase in mean cell length for EC1005 $\mathrm{minB}$ grown in M9gluc, as compared to the corresponding wild-type, was even larger than that predicted for a minicell-producing strain (Donachie \& Begg, 1996). [Also, these results are not in accord with the quantal theory of Teather et al. (1974)]. Still, most non-polar divisions were central and most cells contained $2^{n}$ origins of replication. Analyses performed here showed that there might be a long period of time during which cells with eight origins of replication could divide polarly or centrally, but not non-polarly/non-centrally, which could at least partially explain the low frequency of cells with six origins of replication. The minimum cell length for non-polar, non-central divisions was estimated to be $8.4 \mu \mathrm{m}$ from the cell-size distribution of EC1005. If the delayed nucleoid segregation in EC1005 $\Delta$ minB delayed cell division, however, this minimum cell length might have been even larger in many cells. Although the cell-size distribution of EC1005 $\Delta$ minB was broader than predicted for a minicell-producing strain, few cells $(10 \%)$ were long enough to divide non-polarly/non-centrally, as estimated from the cell-size distribution of EC1005.

A random selection of division sites and an equal delay in nucleoid segregation at central and non-polar, noncentral sites would mean that non-polar, non-central septa would start to appear at a cell length double the length at which central septa started to appear. Here, a few non-polar, non-central septa were found in cells that were shorter than double the length at which central septa started to appear (Fig. 6). At least some of these cells might recently have undergone cell division, which would at least partially explain the occurrence of nonpolar, non-central septa in these relatively short cells.

The size range at which central septa occurred was much larger in EC1005 $\Delta$ minB than in EC1005 (Fig. 6). The smaller size range in EC1005 could have been caused by the Min system inhibiting cell division at the cell centre in cells above a certain length. This would be predicted from the observation that MinCD oscillates around the cell quarter positions instead of around the cell centre in cells above a certain cell length ( $\mathrm{Hu} \&$ Lutkenhaus, 1999; Raskin \& de Boer, 1999a), inhibiting cell division at the cell centre. Accordingly, $\mathrm{Min}^{+}$cells above a certain length have been found to divide at cell quarter positions rather than at the cell centre (Bernander et al., 1995; Botello \& Nordström, 1998).

In this paper, we have presented further quantitative evidence that the $\mathrm{Min}^{-}$phenotype is characterized by impaired nucleoid segregation.

\section{ACKNOWLEDGEMENTS}

We thank Piet de Boer for the kind gift of plasmids pDB156 and 528. This work was supported by the Swedish Natural Science Research Council and the Swedish Cancer Society. A grant from the Knut and Alice Wallenberg foundation enabled us to purchase the microscope and the image analysis equipment.

\section{REFERENCES}

Åkerlund, T., Bernander, R. \& Nordström, K. (1992). Cell division in Escherichia coli minB mutants. Mol Microbiol 6, 2073-2083.

Bernander, R., Åkerlund, T. \& Nordström, K. (1995). Inhibition and restart of initiation of chromosome replication: effects on exponentially growing Escherichia coli cells. J Bacteriol 177, 1670-1682.

Bi, E. \& Lutkenhaus, J. (1990). FtsZ regulates frequency of cell division in Escherichia coli. J Bacteriol 172, 2765-2768.

Botello, E. \& Nordström, K. (1998). Effects of chromosome underreplication on cell division in Escherichia coli. J Bacteriol 180, 6364-6374.

Boyle, D. S., Grant, D., Draper, G. C. \& Donachie, W. D. (2000). All major regions of FtsK are required for resolution of chromosome dimers. J Bacteriol 182, 4124-4127.

de Boer, P. A., Crossley, R. E. \& Rothfield, L. I. (1989). A division inhibitor and a topological specificity factor coded for by the minicell locus determine proper placement of the division septum in E. coli. Cell 56, 641-649.

de Boer, P. A., Crossley, R. E., Hand, A. R. \& Rothfield, L. I. (1991). The MinD protein is a membrane ATPase required for the correct placement of the Escherichia coli division site. EMBO J 10, 4371-4380.

de Boer, P. A., Crossley, R. E. \& Rothfield, L. I. (1992). Roles of MinC and MinD in the site-specific septation block mediated by the MinCDE system of Escherichia coli. J Bacteriol 174, 63-70.

Donachie, W. D. \& Begg, K. J. (1996). 'Division potential' in Escherichia coli. J Bacteriol 178, 5971-5976. 
Grinsted, J., Saunders, J. R., Ingram, L. C., Sykes, R. B. \& Richmond, M. H. (1972). Properties of an R factor which originated in Pseudomonas aeruginosa 1822. J Bacteriol 110, 529-537.

Gullbrand, B. \& Nordström, K. (2000). FtsZ ring formation without subsequent cell division after replication runout in Escherichia coli. Mol Microbiol 36, 1349-1359.

Hale, C. A., Meinhardt, H. \& de Boer, P. A. (2001). Dynamic localization cycle of the cell division regulator MinE in Escherichia coli. EMBO J 20, 1563-1572.

Helmstetter, C. E. \& Cooper, S. (1968). DNA synthesis during the division cycle of rapidly growing Escherichia coli B/r. J Mol Biol 31, 507-518.

Hu, Z. \& Lutkenhaus, J. (1999). Topological regulation of cell division in Escherichia coli involves rapid pole to pole oscillation of the division inhibitor MinC under the control of MinD and MinE. Mol Microbiol 34, 82-90.

Hu, Z. \& Lutkenhaus, J. (2000). Analysis of MinC reveals two independent domains involved in interaction with $\mathrm{MinD}$ and FtsZ. J Bacteriol 182, 3965-3971.

Hu, Z. \& Lutkenhaus, J. (2001). Topological regulation of cell division in E. coli spatiotemporal oscillation of MinD requires stimulation of its ATPase by MinE and phospholipid. Mol Cell 7, 1337-1343.

Hu, Z., Mukherjee, A., Pichoff, S. \& Lutkenhaus, J. (1999). The MinC component of the division site selection system in Escherichia coli interacts with FtsZ to prevent polymerization. Proc Natl Acad Sci U S A 96, 14819-14824.

Jaffé, A., D'Ari, R. \& Hiraga, S. (1988). Minicell-forming mutants of Escherichia coli: production of minicells and anucleate rods. J Bacteriol 170, 3094-3101.

Jaffé, A., Boye, E. \& D'Ari, R. (1990). Rule governing the division pattern in Escherichia coli $\min B$ and wild-type filaments. J Bacteriol 172, 3500-3502.

Margolin, W. (2000). Themes and variations in prokaryotic cell division. FEMS Microbiol Rev 24, 531-548.

Mulder, E., El'Bouhali, M., Pas, E. \& Woldringh, C. L. (1990). The Escherichia coli $\min B$ mutation resembles $\operatorname{gyr} B$ in defective nucleoid segregation and decreased negative supercoiling of plasmids. Mol Gen Genet 221, 87-93.

Nanninga, N. (1998). Morphogenesis of Escherichia coli. Microbiol Mol Biol Rev 62, 110-129.
Nordström, K. \& Dasgupta, S. (2001). Partitioning of the Escherichia coli chromosome: superhelicity and condensation. Biochimie 83, 41-48.

Pérals, K., Cornet, F., Merlet, Y., Delon, I. \& Louarn, J.-M. (2000). Functional polarization of the Escherichia coli chromosome terminus: the dif site acts in chromosome dimer resolution only when located between long stretches of opposite polarity. Mol Microbiol 36, 33-43.

Raskin, D. M. \& de Boer, P. A. (1997). The MinE ring: an FtsZindependent cell structure required for selection of the correct division site in E. coli. Cell 91, 685-694.

Raskin, D. M. \& de Boer, P. A. (1999a). MinDE-dependent pole-topole oscillation of division inhibitor MinC in Escherichia coli. J Bacteriol 181, 6419-6424.

Raskin, D. M. \& de Boer, P. A. (1999b). Rapid pole-to-pole oscillation of a protein required for directing division to the middle of Escherichia coli. Proc Natl Acad Sci USA 96, 4971-4976.

Recchia, G. D., Aroyo, M., Wolf, D., Blakely, G. \& Sherratt, D. J. (1999). FtsK-dependent and -independent pathways of Xer sitespecific recombination. EMBO J 18, 5724-5734.

Sambrook, J., Fritsch, E. F. \& Maniatis, T. (1989). Molecular Cloning: a Laboratory Manual, 2nd edn. Cold Spring Harbor, NY : Cold Spring Harbor Laboratory.

Steiner, W. W. \& Kuempel, P. L. (1998). Cell division is required for resolution of dimer chromosomes at the dif locus of Escherichia coli. Mol Microbiol 27, 257-268.

Teather, R. M., Collins, J. F. \& Donachie, W. D. (1974). Quantal behavior of a diffusible factor which initiates septum formation at potential division sites in Escherichia coli. J Bacteriol 118, $407-413$.

Woldringh, C. L., Mulder, E., Valkenburg, J. A., Wientjes, F. B., Zaritsky, A. \& Nanninga, N. (1990). Role of the nucleoid in the toporegulation of division. Res Microbiol 141, 39-49.

Yu, X. C. \& Margolin, W. (1999). FtsZ ring clusters in min and partition mutants: role of both the Min system and the nucleoid in regulating FtsZ ring localization. Mol Microbiol 32, 315-326.

Yu, X. C., Tran, A. H., Sun, Q. \& Margolin, W. (1998). Localization of cell division protein FtsK to the Escherichia coli septum and identification of a potential N-terminal targeting domain. J Bacteriol 180, 1296-1304.

Received 18 February 2002; revised 31 May 2002; accepted 24 June 2002. 